\title{
Waardenburg's Syndrome - A Rare Entity
}

\author{
Rahuldeb Chattopadhyay PGT, \\ Maj. A. K. Mehta Reader, Dept. of ENT \\ AFMC, Pune 411040
}

\begin{abstract}
A
three year old female patient presented in ENT OPD with complaints of inability to hear and speak since birth. The child was born to consanguineous parents. The other sibling was normal and there was no family history of congenital hearing loss. The prenatal and perinatal history was normal. General, physical and systemic examination did not reveal any abnormality and all milestones were corresponding to the age. White forelock of hair was present in the frontal region and there were white hair in the (R) eyebrow (Fig. 1). Ear examination did not reveal any abnormality of the pinna, external auditory canal or tympanic membrane. Nose and throat were normal. Free field distraction tests did not produce any response. Ophthalmological examination revealed bilateral heterochromia iridium with hypertelorism and outward displacement of lacrimal punctum. Routine blood and urine examination and radiological examination of temporal bone was normal. IQ tests were normal. Free field audiometry failed to produce any response and BERA revealed profound bilateral sensorineural hearing loss. The patient was advised hearing aid and speech therapy.

\section{Discussion}

Waardenburg's syndrome is responsible for $1-2 \%$ of all congenital hereditary hearing losses. It has an autosomal dominant mode of inheritance. Waardenburg (1951) first discribed this syndrome after finding 12 cases among 840 persons in 5 Dutch institutions. The characteristic features of this syndrome are, 1) Dystopia canthorum (lateral displacement of the medial canthi and lacrimal puncta), 2) Broad nasal root, 3) Confluence of Medial portions of eyebrow, 4) Partial or total heterochomia iridium, 5) Circumscribed albinism of frontal head hair (white
\end{abstract}




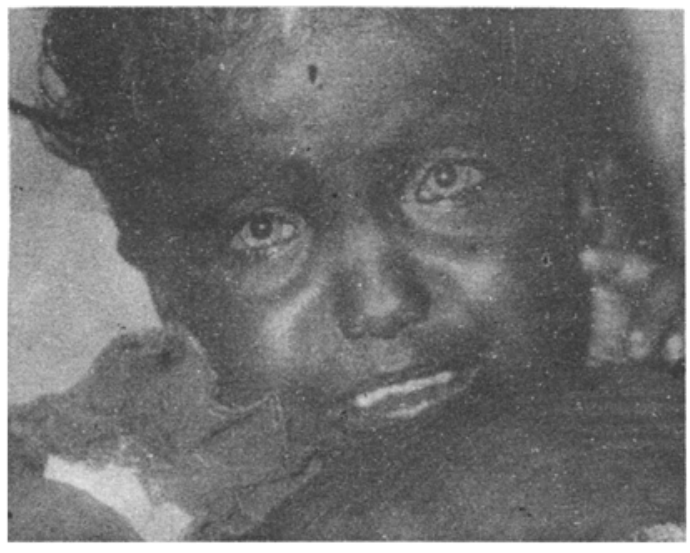

Fig. I Characteristic facial appearance of the patient with Waardenburg's Syndrome.

fore lock), 6) Sensorineural hearing loss (unilateral/ bilateral). Wang et al (1981) have emphasized the extreme variability in expressivity of this syndrome and pionted out that many members of families with this hereditary syndrome may or may not have hearing loss and may have only one or more of the other expressions of this disease like albinism, vitiligo, premature greying of hair, prognathium, short metacarpals, clinodactyly rounded nasal tip, full lips, cleft palate, cardiac murmurs or vestibular abnormalities. Arias (1980) classified Waardenburg's syndrome into two distinct types - Type-I. patients with Dystopia Canthorum, Type-II, patients not associated with Dystopia canthorum. Associated diseases that have been reported are Hirschsprung's syndrome, oesophageal atresia, meningocele. Fisch (1959) observed three distinctive audiometric patterns1) Bilateral severe hearing loss with only slight residual hearing for low frequencies, 2) Bilateral moderate hearing loss, most severe for low frequencies with normal hearing for $6000 \mathrm{~Hz}$ and $8000 \mathrm{~Hz}, 3$ ) Unilateral moderate hearing loss. Post mortem exam. of temporal bone revealed atrophy of organ of corti, stria vascularis and cochlear neurons without any apparent abnormalities of vestibular sense organ (Fisch, 1959). Rarey and Davis (1984) found the same and also association of Waardenburg's syndrome with Hirschsprung's disease. Marcus (1968) found frequent anbnormalities of vestibular response and radiographic evidence of inner ear anomalies.

\section{References}

1. Arias $S$, (1980): Waardenburg's syndrome - two distinct types. American Journal of Medicine and Genetics $9: 99$ -100 .

2. Fisch L, (1959) : Deafness as part of an hereditary syndrome. Journal of Laryngolgoy and Otology, $73: 355-382$.

3. Marcus RE, (1968) : Vestibular function and additional findings in Waardenburg's syndrome. Acta Otolaryngologica Suppl. (Stockh) $229: 1$ - 30.

4. Rarey KE, Davis LE (1984) : Inner ear anomalies in Waardenburg's syndrome associated with Hirschsprung's disease. International Journal of Paediatric Otorhinolaryngology, $8: 181-189$.

5. Waardenburg PH, (1951): A new syndrome combining developmental anomalies of eyelids, eyebrows and nose root with pigmentary defects of the iris and head hair with congenital deafness. American Journal of Human Genetics, $3: 195-253$.

6. Wang-L, Karmody CS, Pashayan H, (1981) : Waardenburg's syndrome : Variations in expressivity. Otolaryngology Head and Neck Surgery 89 : 666-670. 